\title{
VALUE OF WISDOM THROUGH EXPERIENCE: SUSTAINABLE HERITAGE
}

\author{
CHRISTOPHER J. HOWARD \\ The Catholic University of America, USA
}

\begin{abstract}
Architectural heritage, like cultural heritage, is a very nourishing resource, providing meaning and wisdom from experience for the next generation. Without heritage, alienation, apathy and ignorance take hold. Human beings thrive from connections between past, present, and future. Yet, today, the field of architecture suffers from a lack of connection to the past. Effects from this can be seen in issues that face the field of architectural heritage, manifest through indifference, ignorance and neglect. Architecture in the past, built upon architectural heritage, both figuratively and literally. Design relied on precedence through documentation and analysis. Existing architecture found new life through adaptive reuse. There was a very comfortable and familiar interaction between old and new. Today, little reference or reverence is given to the past. This approach disengages with heritage, creating a chasm between old and new. The need for architectural heritage has become one dimensional, with a less compelling reason to care beyond an appreciation for what was once deemed valuable. These structures become artifacts of nostalgia in a museum culture. How did we get to a point where architectural heritage mattered so little? It is worth examining the trajectory of and forces behind this development, as well as the current state of architectural education. A review of the 128 accredited schools of architecture in the United States, show that there are only 22 schools of architecture that have a historic preservation component of the curriculum, and only 3 of those schools teach traditional design as a continuum from the past. Architecture schools must invest in heritage as an educational resource and engage with preservation. Through documentation, analysis and history, to learn aesthetic, construction and cultural lessons, the next generation may lead the way toward increased appreciation and reconnection with our architectural heritage.
\end{abstract}

Keywords: resource, wisdom, experience, connection, architectural education, tradition.

\section{INTRODUCTION}

It is always rewarding to hear a good story from your grandparents about your background. To hear more about what makes you, you. Receiving wisdom from them is just as rewarding. You know they have been through trials in their life and now out of love for you, are compelled to help you navigate the future more successfully. Cultural heritage, like genealogical heritage, can be a very rewarding and nourishing resource in this same way, by providing both memory and practical meaning as a necessary part of our human experience in living with one another across time and space successfully.

One of the most evident sources of cultural heritage is that of our built environment, replete with tangible manifestations of our cultural experiences. This substantial provision merits our appreciation in knowing what it has to offer. Our architectural heritage can remind us of cultures past through association, it can represent something of historical importance like an event, and it can show us how to build and design well. Our built culture can teach us about who we were, who we are, and who we want to be.

Like a good story, we are drawn to our architectural narrative. We visit high frequency tourist locations in historic centers, not because it is merely our past, but because there is something good and worthy there (Fig. 1). It is not just that it is old, but that it is successful. It conveys a lesson and a story of cultural meaning that we can relate to as a connected member of society. In order to understand its true value, we must choose to cultivate a good and connected relationship with architectural heritage. 


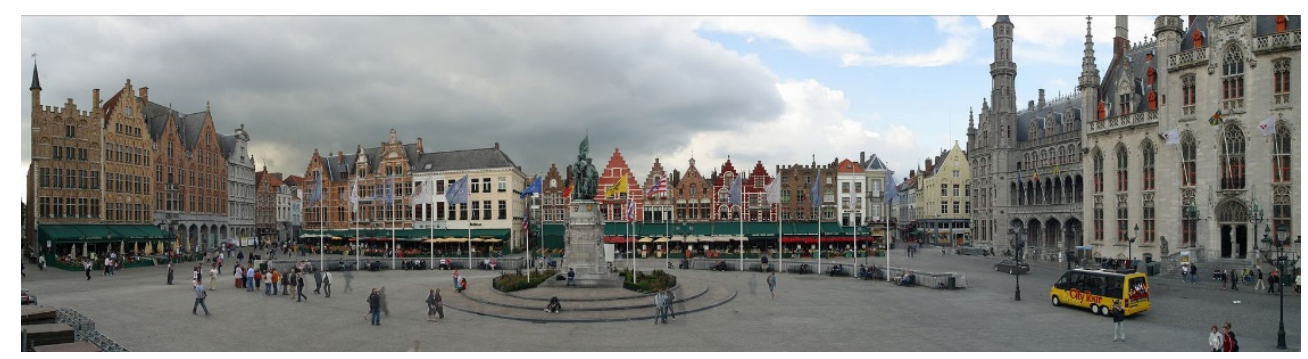

Figure 1: Brugge, market square. (Source: Cavalier JY-Photos personnelles, CC BY 3.0, via Wikimedia.)

It should be clear that conserving our built heritage is a cultural imperative. We should want to extract as much value from it as possible and understand our role in space and time as part of a link from that past, through us to the future. A figurative passing of the torch occurs in this relationship, where we have the opportunity to leave our own mark of interpretation and not just preserve for posterity: challenge assumptions, be critical, but appreciate and rely on good work, already done well, for our sake.

A denunciation of this heritage on the other hand, leaves a void. What fills that void is alienation, ignorance and apathy. "I don't relate as much as I have, and therefore I don't know as much about, consequently I don't care as much as I did". These attitudes then understandably set up an antagonistic relationship towards the object of inheritance. If this attitude prevails without a "hand off", the connection to the source is severed and ultimately dies. Apathy, born from disregard for built heritage, is exactly what gave rise to the preservation movement. Preservation became an explicit reaction against acts that are incongruent with cultural sustainability, whether, intentional or not. The neglect and ignorance of our valued built heritage is in effect an act of cultural violence, and loss.

While there have been great strides and exceptional outcomes as a result, there seems to be a trajectory of continuing systemic apathy and ignorance about heritage architecture. It can be seen in callous development projects, insensitive architectural interventions and preservation malpractice. With such a well-established and supported preservation culture today, how can this be?

\section{OUR CULTURES}

In looking at relevant aspects of our built heritage to help answer this question, we should understand the broader cultural climate, as it is always connected to its physical manifestation. Compared to traditional society our current culture has shifted its focus in meaningful ways as a post-industrial society that can generally be described as: pluralistic, autonomous, spread-out, consumerist, technologically advanced/virtual, bureaucratic, and "modernist". These traits certainly have an impact on our collective perspectives about our built heritage. Arguably, the most conspicuous effect is our post-industrial consumerist preoccupation with the novelty of the "new" at the expense of the "old". The result is development apathy, satiating those broad cultural desires, by the destruction of historic buildings and places.

However, for the purposes of this paper, I concentrate only on the relevant subjects of architecture, preservation and education, where direct stewardship of our built environment is expected. American preservationist James Marston Fitch correctly identifies this as an issue. "This revolutionary reversal of man's historic relationship to the environment suddenly 
imbues all material evidence of the human past with new significance...but it is an issue of special poignancy to those who are entrusted with the care of the artistic heritage" [1]. The issues of heritage culture today go well beyond technical aspects of preservation, and warrant shedding light in both architecture and preservation worlds in order to enact needed meaningful change.

\section{ARCHITECTURAL CULTURE}

From the inception of architecture up to the "modernist" era approximately 100 years ago, architecture was just architecture. Today, the pre-modernist culture of building is called "traditional", as in "to pass on". Traditional architectural culture accumulated a knowledge of building based on roughly 4,000 years of experience. These experiences were always forward-looking in trying to develop the best practices for human habitation and flourishing.

This passing on from culture to culture, through time, results in an inherently sustainable, timeless, universal and accessible architecture. Traditional architecture responds to the essential needs of "architecture" in service to human beings, from the most basic pragmatic purpose of providing shelter, to more nuanced usages per building type, to best construction practices, to imbuing buildings with a transcendent purpose through language and natural aesthetic principles of objective beauty.

The traditional architectural aesthetic is best described as a compositional language, using vocabulary, syntax, diction, and decorum to compose ordered artful buildings that seek to discover and imitate beauty found in nature. These principles are well represented through the ancient architectural theorist Marcus Vitruvius Pollio who cited: firmness, commodity and delight, as the ingredients for good building and further for good architecture, a need to accommodate order, arrangement, proportion, symmetry, decorum and economy [2]. Urbanistically, the outcome is that of buildings that are in dialogue as parts of a larger, unified, harmonious whole (Figs 2 and 3). In short traditional architecture can be defined as "that way of building which makes serious use of the familiar symbolic forms of a particular culture of a particular people in a particular place" [3]. While the vast majority of the architectural world today is of the modernist aesthetic, there is a smaller contingent of traditional modern practitioners designing and building today, participating in a continuation of traditional culture.

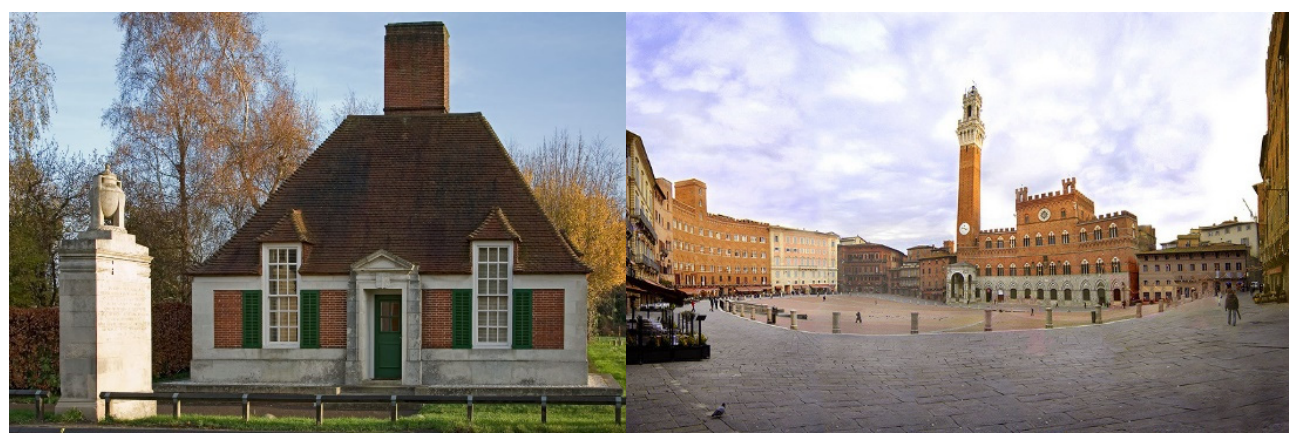

(a)

(b)

Figure 2: (a) Edwin Lutyens' Broughton Memorial Lodge. (Source: WyrdLight.com, CC BY 3.0, via Wikimedia); (b) Piazza del Campo. (Source: Ricardo André Frantz Own work, CC BY-SA 3.0, via Wikimedia.) 


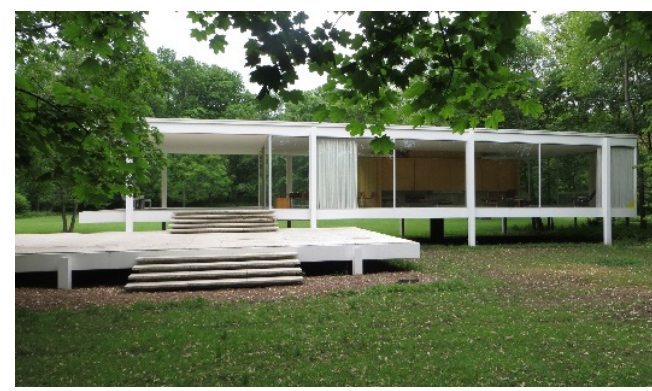

(a)

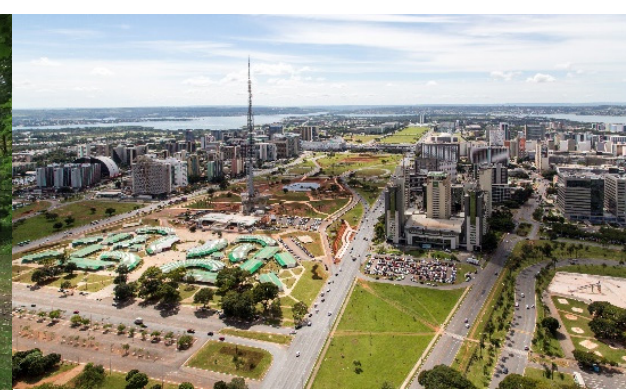

(b)

Figure 3: (a) Mies Van der Rohe's Farnsworth House. (Source: David Wilson); (b) City of Brazilia. (Source: Governo do Brasil - Portal da Copa, CC BY 3.0, via Wikimedia.)

Contemporary architectural culture is largely influenced by "modernist" architecture. This approach to architecture, developed in the early 20th century, was an attempt to reflect the cultural climate of the time, introducing an architecture that was wholly new as a complete departure from all architecture of the past. Where traditional windows were tall and vertical, modernist windows will be wide and horizontal. This architecture intended to not only present a new architecture but was also determined to supplant tradition to a point of being irrelevant. The impact of this architectural revolution was fast and pervasive. One of the pioneers of modernism, Le Corbusier, directly describes this initiative. "A great epoch has begun. There exists a new spirit. There exists a mass of work conceived in the new spirit; it is to be met with particularly in industrial production" [4].

The aesthetic character of modernist architecture is antithetical to tradition and can generally be described as trying to achieve a "machine aesthetic" with heavy emphasis on technological influence in being clean, systematized, functional, pure and devoid of human reference. "A house is a machine for living in" (Le Corbusier [4]). Without standard design principles, there are no "rules" per se, which results in the arbitrary and abstract. Modernist architecture is generally spare without ornamentation or detail, and therefore relies on the form for expression. It does not have an established language and for that reason tends to stand on its own, as an autonomous self-referential creation regardless of context. There is also a sense of employing emotion as means of being compositionally compelling, from eliciting discomfort through discordance, or awe through sublime indifference to gravity. Modernist architecture is also intrinsically ephemeral or anachronistic as the "spirit of the age" dictates that all creations be completely original all the time [5].

Modernist urbanism is consistent with the aims of its architectural approach in that it is whatever "traditional" is not. Modernist urbanism does not attempt to create harmonious integrated space defining public areas, but rather imagines architectural space as infinite and fluid.

\section{PRESERVATION CULTURE}

It is a natural social inclination to preserve, something we have been doing from the beginning. As time and experience pass, more heritage accumulates, and what follows, is a conscious effort to retain value. One of the earlier occurrences can be found in ancient Rome with a multitude of accumulated monuments and memorials coated with a thick layer of meaning, as symbols of the ethos of Rome. Rome restored monuments and repurposed 
buildings from the past to keep them "alive". Emperor Theodoric called for the repair and conservation of imperial buildings by allowing for their adaptive reuse. "Keeping them (monuments) in use forestalls the decay of old age" [6]. This cultural instinct continued into the middle ages by repurposing old parts and on to the renaissance where Ancient Rome became a wellspring to study and learn from, in an effort to re-present classical architecture with a modern interpretation. Similar traditional societies developed a variety of techniques to preserve their architectural inheritance, all with the common cause of conserving a deeply rooted connectedness across time and space, where old and new were members of a family.

Traditional architectural heritage rests on the idea of how existing buildings can continue to be of use. Because of this approach, there is a developed knowledge base about how best to treat heritage whether to restore, renovate, add onto, or build around. This familiarity, also allowed buildings to perish, knowing that they would likely be replaced by something similar, new and perhaps better, as in an ecological cycle of life.

Current day preservation practice can trace its roots back to the 19th century. Two main figures are helpful in understanding the breadth of theories in how to deal with built heritage. On one end is Viollet Le Duc, sympathetic to the idea of heritage being a part of a living tradition in attempting to engage with the subject as a work of art through renovation and restoration. "To restore an edifice means neither to maintain it, nor to repair it, nor to rebuild it; it means to reestablish it in a finished state which may in fact never have existed before at any given time" [7]. If parts of the original design were not known through documentation, then it made sense to rely on well informed conjecture to restore "in a manner suitable to its own integrity" [7]. One can imagine the human body as an analogy to this method. If a body part were lost, you would restore it with "like" part, in order to make it whole again. John Ruskin represented the other end of the spectrum, with a more deferential approach to preservation. His philosophy was one of curatorial repair, anything beyond that, was an act of destruction. "We have no right whatever to touch them. They are not ours. They belong partly to those who built them, and partly to all the generations of mankind who are to follow us" [8].

The current state of preservation is more aligned with the Ruskinian approach. This is, in part, due to the current state of architectural culture and its relationship with built heritage. This awkward relationship lacks the ability or desire to connect, but rather a desire to distance and contrast as much as possible. With this attitude, architectural heritage is not something to be developed, but rather just an artifact or relic, meant to stay in the nostalgic past. The focus on empirical authenticity and scientific embalming of heritage, can be explained by the specialization of the preservation practice that consists largely of non-architects, and as such severely limits any conversation about architectural design value within the field. In the Venice Charter, the preeminent international source for preservation, we see a clear directive that reinforces these tendencies of contrast, and containment. Article 9 of the Charter addresses both issues.

To restrict intervention (or the Viollet le Duc approach), the charter states that any treatment "must stop at the point where conjecture begins" [9]. Differentiation is reinforced by a decree that additions to historic buildings need to bear a "contemporary stamp", which can easily be interpreted as "modernist". In short, preservation practice today, has become more about a subject merely for studying and keeping and less about being full, active, and inclusive member of the built environment.

\section{ARCHITECTURE AND PRESERVATION CULTURES COLLIDE}

What should be gleaned from these comparisons of architecture and preservation culture is that something has been lost. When comparing traditional and modernist architectural 
cultures the dichotomy is unavoidable, where the loss is not that there is a new way of thinking about architecture, but that it is at the expense of the other. The difficulty that this presents is simply that there is substantial disregard for the full value of inheritance, which is largely traditional. It should not be a surprise then, with the pervasive ideology of modernism in the architectural profession and schools, that heritage has taken a hit, due to detached engagement that sets up an irreconcilable relationship with the past.

Traditional architecture is severely hampered by substantial loss over the last century. What contemporary traditional architecture can offer today, is hope. A willing inheritor of traditions of the past, building next to the old and establishing a more compatible relationship once again. In this way the language and culture of traditional heritage can be passed on for continued reinterpretation and improvement, as a living didactic of traditional heritage. "It is an important feature of traditions that they adapt and change. So, while change accelerates so should the adaption of traditions as a matter of importance to all of us. If change occurs without the transmission of culture, then culture itself dies; culture cannot be created anew every day. The evolutionary nature of tradition is something often ignored by supporters and opponents alike. It is important that history - that which measure our distance from the past - is not confused with tradition - the past living through us" [10].

Born of good intentions, the preservation movements' efforts to document, discover, and use technology to record, are impressive. However, the current trend compromises these efforts. The dictates to have a strict non-interventionism policy and a "contemporary stamp", sets up an isolationist and adversarial, relationship with the past, which is inherently contrary to the preservations overarching cause. Due to the perception that traditional architecture is irrelevant, and essentially dead, we are certain to see an increase of apathy, ignorance and marginalization of heritage.

Within this prevailing context, the need for architectural heritage becomes one dimensional, with a much less compelling reason to care for heritage beyond an appreciation for what was once deemed culturally valuable. The general appreciation for the past and memories it invokes is of value for sure, but it does not sufficiently tap into the substantive value of the resource. "This application of historical or archaeological methodology to living buildings and places is like the study of wildlife through taxidermy. It has the effect of turning living organisms into dead specimens and takes away the life that made them worthy of study in the first place" [11].

Today's culture speaks loudly and clearly with a conviction that environmental sustainability is more than a worthy endeavor, but a necessary one. Our world is given to us as a resource, and as such we are responsible for being good stewards. Our built environment, like our natural environment, is a valuable resource that we need to protect in order to restore. Some of the lessons that have been learned and utilized in traditional building cultures are very much literally sustainable in terms of, durability, flexibility - through adaptive reuse, use of natural materials with low embodied energy, geographic settlements being built on a smaller footprint of land, and other naturally sustainable traditional building practices. The cultures that produce these buildings have something to say to us in the present about how best to sustain. In these ways, environmental sustainability and heritage are inextricably linked through a common cause of conservation.

\section{A PATH FORWARD: TO CONSERVE AND EDUCATE}

What we know is that there continue to be issues with the protection of built heritage that is likely manifest through our attitude toward built heritage. We are simultaneously discarding the culture of heritage while seeking to prop up its creation. If we are able to acknowledge that there is a connection between our current attitude and its vulnerability, then we need to 
look at ways to restore our relationship with the past in order to move beyond preservation for preservation sake, into the future.

\subsection{Conservation vs. preservation}

In a book entitled "The Future of the Past", Professor Steven Semes, makes a compelling proposal that offers a path forward. Through critical analysis of historic preservation theory and practice, he recognizes the issues of incongruity between current architecture and preservation culture with the past. His response is to propose an optimistic paradigm shift through something he calls "A Conservation Ethic". The conservation ethic is a perspective that uses the term conservation meaningfully in comparing it to the conservation of Natural resources, where the resource is not presumed dead, but alive and worth keeping so. "The conservation ethic does not mean a ban on change; rather, it means the management of change to avoid unnecessary loss. Conservation is tied to the concept of culture, which, as Hannah Arendt reminded us, is of Roman origin, deriving from colere - 'to cultivate, to dwell, to take care, to tend and preserve' - a term that ultimately "indicates an attitude of loving care" "[12]. The conservation ethic suggests the focus be on a "sense of place" rather than "sense of time", as the value of heritage buildings lies in what they do for us on an experiential and existential level. Further, the ethic espouses a relationship of compatibility between new and old over the current relationship of distance and differentiation. This would amount to modernist and traditional not needing to be adversarial, but simply acknowledge the differences and do what they do well in their own contexts.

Adopting this approach opens the doors for us to more fully accept lessons from the past that have been gained through experience, to more successfully sustain heritage by putting it to good use. More options are opened for heritage engagement where the "one size fits all" model of using only contemporary/modernist additions can be broadened to allow for traditional know-how and appropriateness within a traditional context. This would go a long way toward setting up a more inclusive versus isolationist relationship.

\subsection{Architectural education}

The best conduit for this effort is likely through education. By placing a strategic focus on improving the dissemination of knowledge, we can better insure in future architects and preservationist an understanding of and commitment to caring about our built heritage.

Historically, architectural education was achieved in architectural guilds or offices and involved a pretty well-rounded exposure to all disciplines of building including: construction, craft, trades, engineering, urban planning, science, and art. Eventually a more formal mode of training developed within architecture schools. The Ecole des Beaux-Arts in early 19thcentury France, was arguably the hay-day of this model (Fig. 4).

"A measured drawing is required by the Beaux-Arts Institute course, not as reference material, but because it is an excellent training" [13]. Traditional education was about the continuum of learning from the past in order to advance into the future. This meant and continues to mean looking at precedence - those buildings that came before as exemplary, to help understand how best to solve a particular problem. From a design standpoint, this involved analysis of precedence through documentation, by visiting the building and drawing the subject, allowing that process to instill in you an intimate understanding of the buildings' compositional essence.

Contemporary architecture schools made a clear break from the past as modernisms' cause overtook architectural culture. The most notable of early modernist architecture schools was 


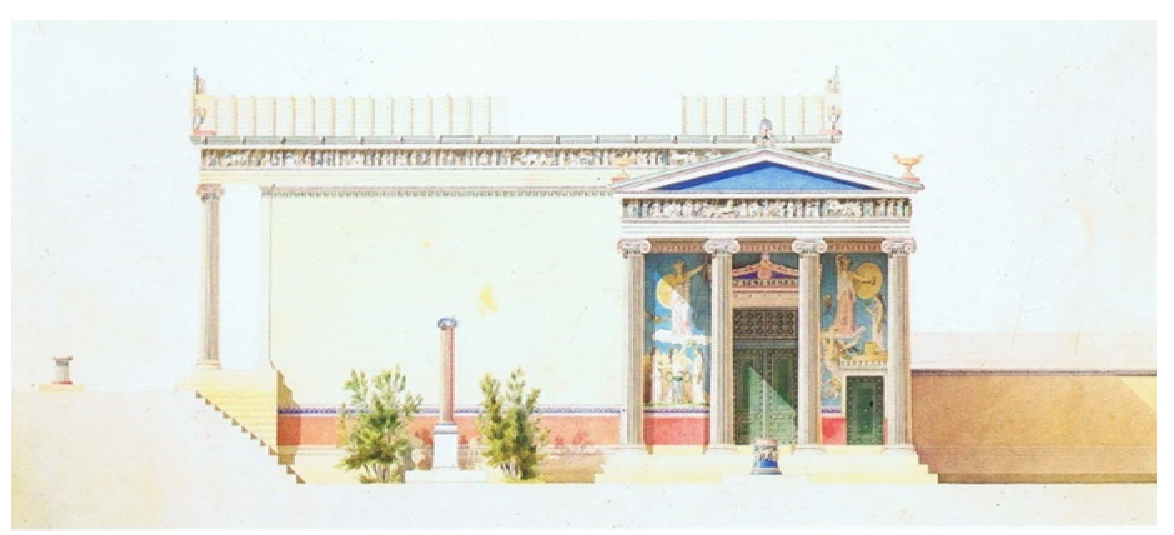

Figure 4: Precedence study. (Source: Jacques Tetaz in "Rome, Paris Athens, p. 183.)

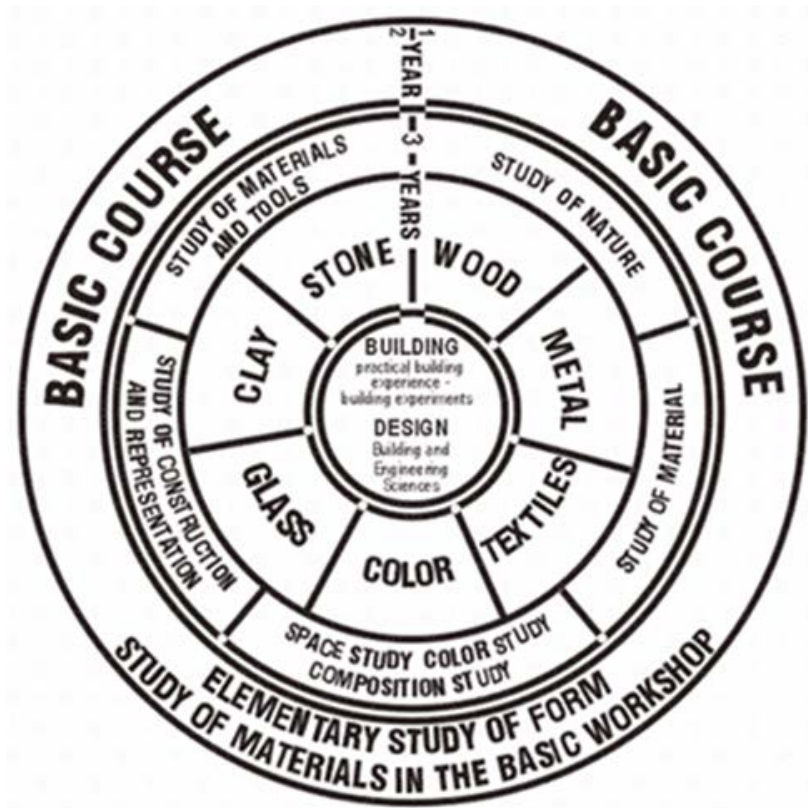

Figure 5: Bauhaus curricular diagram. (Source: Oliver Tomas.)

the Bauhaus in Germany. Bauhaus students were encouraged to produce designs based on subjective perception in lieu of precedence. A diagram of the curriculum illustrated in Fig. 5 with concentric circles, charts the curricular path from the outside, at the beginning, to the inner circles, at the end.

Foundational courses focused on study of form and material in workshops. Then, focus went to the study of color theory, nature, tools, construction, representation and composition. A dedication to craft with materials followed, where they were meant to be mastered through years of honing the craft. Only after graduating did a select few get invited to the study of buildings. Today, most schools are based on this model. 


\subsection{Architectural education in the United States}

A review of today's architecture college curricula in the United States provides an indication of whether there is any engagement with or evidence of learning from the past. The information from this review was acquired solely from each schools' website. Further research through correspondence with the school would be necessary to completely confirm these findings.

A review of the list of accredited architecture programs in the United States, provided by the National Council of Architectural Registration Boards, shows there are only 3 out of 128 schools that teach traditional architecture as an integrated part of the curriculum.

Of approximately 5,300 colleges in the United States, only 59 offer a degree in historic preservation. Only 22 schools offer both architecture and historic preservation.

In a more focused review of architecture schools, I identify the top 10 schools in the United States this year, through the assessment of three primary media sources [14]-[16]. For each, I looked at the basic undergraduate curriculum to see if there were any indications of using heritage as a teaching mechanism. The courses targeted for this investigation were: Architectural Design Studio, Architectural History, Building Construction, Environmental Sustainability and any relevant historic preservation electives. For this review, I developed questions per course, to help ascertain relevant information. The result is in Table 1.

These findings are not surprising and illustrate a lack of learning from the past. In design courses, when precedence is used, it is largely just for gleaning abstract formal compositional lessons, but otherwise leans heavily on subjective creation. Though history is required, the question becomes whether a historicist account that supports a deterministic/chronological valuation of architectural history. This approach largely dismisses the value of past traditional architecture, ignoring contemporary traditional examples, and becomes an exercise in trivial pursuit.

These reviews demonstrate that in schools of architecture there is room for improvement to be more inclusive with regard to the sustainability of traditional heritage culture, through accommodations similar to those provided for sustainability of the environment. Additionally, the relationship between architecture schools and preservation programs ought to be more integrated. The following are some basic recommendations that can be taken to achieve these goals:

- Adopt a dual design studio track in architecture schools, that has both modernist and traditional design studios, allowing for the opportunity to become versed in the language of traditional architecture.

- Ensure that history courses offer a holistic narrative account of human efforts to build and understand the connections between architecture beyond chronology.

- Develop building construction courses that include traditional/inherently sustainable methods of building and incorporate opportunities to work in crafts.

- Incorporate rigorous documentation and analysis of heritage buildings into the curriculum as "cultural sustainability".

- Invest in the adoption of more historic preservation programs with colleges.

- Coordinate and overlap course work between architects and preservationists.

The expected tangible result of this would be an infusion of sensitivity and knowledge in the work force of architects, engineers, scientists, and preservationists. Architects would be more capable of answering the call to engage traditional heritage as creative expert practitioners that can bring aesthetic valuation back into the fold. 
Table 1: Review of top 10 US architecture school curricula regarding heritage.

\begin{tabular}{|c|c|c|c|c|c|c|c|c|c|c|}
\hline & \multicolumn{10}{|c|}{ Educational institutions } \\
\hline Curriculum review questions & 1 & 2 & 3 & 4 & 5 & 6 & 7 & 8 & 9 & 10 \\
\hline \multicolumn{11}{|l|}{ Architectural design } \\
\hline $\begin{array}{l}\text { Is there any indication of using } \\
\text { precedence as a design tool? }\end{array}$ & $\mathrm{Y}$ & Y & $\mathrm{N}$ & Y & $\mathrm{N}$ & $\mathrm{N}$ & Y & Y & Y & $\mathrm{N}$ \\
\hline $\begin{array}{l}\text { 2. Is there any indication of using } \\
\text { traditional precedence as a design tool? }\end{array}$ & $\mathrm{N}$ & $\mathrm{N}$ & $\mathrm{N}$ & $\mathrm{N}$ & $\mathrm{N}$ & $\mathrm{N}$ & $\mathrm{N}$ & $\mathrm{N}$ & $\mathrm{N}$ & $\mathrm{N}$ \\
\hline \multicolumn{11}{|l|}{ Architectural history } \\
\hline $\begin{array}{l}\text { 3. Is a full history of architecture offered } \\
\text { (4000 BC to current }) \text { ? }\end{array}$ & Y & $\mathrm{Y}$ & Y & $\mathrm{Y}$ & $\mathrm{Y}$ & $\mathrm{Y}$ & Y & Y & $\mathrm{N}$ & Y \\
\hline $\begin{array}{l}\text { 4. Is there any reference to learning } \\
\text { formal lessons from historic } \\
\text { architecture? }\end{array}$ & Y & $\mathrm{N}$ & $\mathrm{N}$ & $\mathrm{N}$ & $\mathrm{N}$ & $\mathrm{N}$ & $\mathrm{N}$ & $\mathrm{N}$ & $\mathrm{N}$ & $\mathrm{N}$ \\
\hline \multicolumn{11}{|l|}{ Building construction } \\
\hline $\begin{array}{l}\text { 5. Is there any clear reference to learning } \\
\text { from traditional construction } \\
\text { techniques? }\end{array}$ & Y & $\mathrm{N}$ & $\mathrm{N}$ & $\mathrm{N}$ & $\mathrm{N}$ & Y & $\mathrm{N}$ & $\mathrm{N}$ & $\mathrm{N}$ & $\mathrm{N}$ \\
\hline \multicolumn{11}{|l|}{ Environmental sustainability } \\
\hline $\begin{array}{l}\text { 6. Is environmental sustainability a } \\
\text { required and available part of the } \\
\text { curriculum? }\end{array}$ & Y & Y & Y & $\mathrm{Y}$ & $\mathrm{Y}$ & $\mathrm{N}$ & Y & Y & $\mathrm{Y}$ & Y \\
\hline \multicolumn{11}{|l|}{ Historic preservation or other } \\
\hline $\begin{array}{l}\text { 7. Are there any courses, concentrations } \\
\text { or degrees offered within the } \\
\text { architecture school, related to historic } \\
\text { preservation? }\end{array}$ & $\mathrm{N}$ & $\mathrm{N}$ & $\mathrm{Y}$ & $\mathrm{N}$ & Y & $\mathrm{N}$ & $\mathrm{N}$ & $\mathrm{N}$ & Y & $\mathrm{N}$ \\
\hline $\begin{array}{l}\text { 8. Are there any programs within the } \\
\text { university and outside of the } \\
\text { architecture school, related to historic } \\
\text { preservation? }\end{array}$ & $\mathrm{N}$ & $\mathrm{N}$ & $\mathrm{N}$ & $\mathrm{N}$ & $\mathrm{N}$ & $\mathrm{N}$ & $\mathrm{N}$ & $\mathrm{N}$ & $\mathrm{N}$ & Y \\
\hline
\end{tabular}

Additional benefits would include the involvement of traditional architects as experts in historic investigations, helping to determine how existing buildings were built and how they can be re-built or added on to given modern construction techniques that respond in particular to fire and seismic considerations. Documentation and analysis by trained architects (see example in Fig. 6) would improve as well, given the astute focused eye of an expert who speaks the language fluently. On the preservationist side, architects being exposed to preservation techniques and principles, would have a better appreciation for and knowledge about preservation in order to more collaborative.

\section{CONCLUSION}

The current relationship we have with heritage architecture does not seem sustainable, despite the great strides and efforts of the preservation movement. There are too many elements that are constricting the vitality of our heritage through apathy, ignorance or over-protection that may ultimately lead to a point of suffocation. 


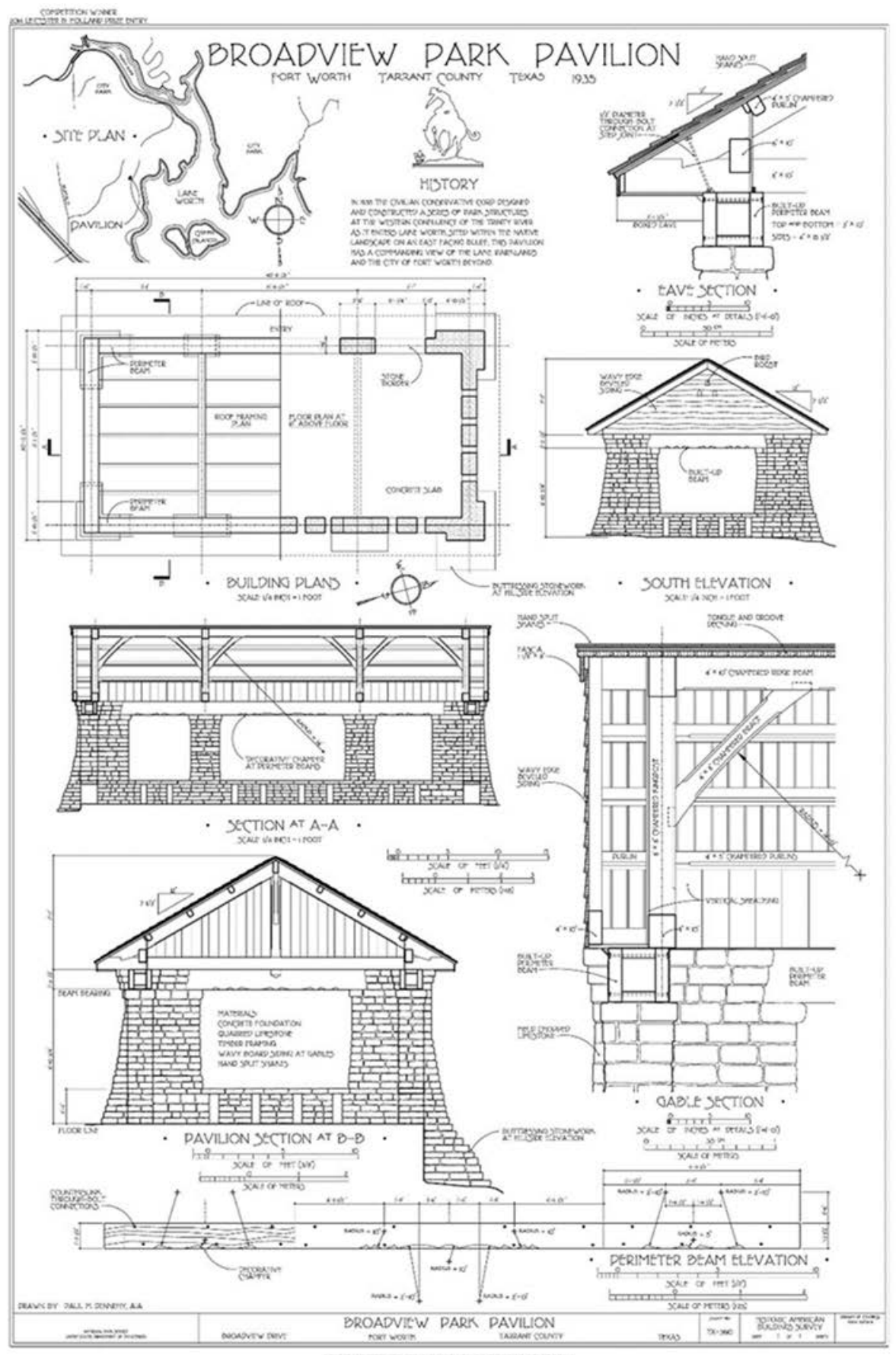

Figure 6: Example of heritage documentation to be produced by students or architects. (Source: Drawn by Paul M. Dennehy for the US Department of Interior, National Park Service-Historic American Building Survey, 2014.) 
If, however, we act to bring about more balance, cooperation and familiarization, through education, we can better facilitate a love for heritage. With an increase in active living traditional heritage as part of a continuum, the "conservation ethic" would be in good hands in reanimating heritage buildings by further incentivizing a more proactive, open-minded and creative attitude. Such changes may help reinforce the importance of architectural heritage, as a necessary means to cultural sustainability, bringing it off the dusty shelf and back into our lives.

\section{REFERENCES}

[1] Fitch, J.M., Historic Preservation: Curatorial Management of the Built World, University of Virginia Press: Charlottesville, p. 23, 1990.

[2] Morgan, M.H., Vitruvius: The Ten Books of Architecture, Book I, Chapter II, Dover Publications: New York, 1960.

[3] Marcantonio Architects Blog, Traditional architecture FAQs, New York. http://blog.marcantonioarchitects.com/traditional-architecture-faq/. Accessed on: 29 Jul. 2019.

[4] Le Corbusier, Towards a New Architecture, Dover Publications: New York, pp. 3-4, 1986.

[5] Brolin, B.C., Architecture in Context: Fitting New Buildings with Old, Van Nostrand Reinhold: New York, p. 7, 1980.

[6] Kostof, S., A History of Architecture: Rituals and Settings, Oxford University Press: New York, p. 272, 1995.

[7] Viollet le Duc, E.-E., The Foundations of Architecture, George Braziller: New York, pp. 195-223, 1990.

[8] Ruskin, J., The Seven Lamps of Architecture, Ballantyne, Hanson: London, p. 358, 1906.

[9] International Charter for the Conservation and Restoration of Monuments and Sites (The Venice Charter), 1964.

[10] Adam, R., Classic Columns: 40 Years of Writing on Architecture, Chapter 5, Cumulus: London, 2012.

[11] Adam, R. \& Hardy, M. (eds), Tradition today: Continuity in architecture and society. I.N.T.B.A.U, WIT Press: Southampton and Boston, p. xi, 2008.

[12] Semes, S.W., The Future of the Past: A Conservation Ethic for Architecture Urbanism, and Historic Preservation, W.W. Norton: New York, pp. 35-253, 2009.

[13] Harbeson, J.F., The Study of Architectural Design, W.W. Norton: New York, p. 165, 1927.

[14] USA Today Top 5 architecture colleges in the US. http://classifieds.usatoday.com/ blog/education/top-5-architecture-colleges-usa/. Accessed on: 29 Jul. 2019.

[15] Gilmore, D., Top Architecture Schools of 2019. www.architecturalrecord.com/ articles/13611-top-architecture-schools-of-2019. Accessed on: 29 Jul. 2019.

[16] Archdaily, The best architecture schools in the US 2019. www.archdaily.com/901435/ the-best-architecture-schools-in-the-us-2019. Accessed on: 29 Jul. 2019. 